\title{
Efficient Near-Infrared Light-Driven Hydrogen Evolution Catalyzed by a Saddle-Distorted Porphyrin as a Photocatalyst
}

\author{
Hiroaki Kotani, ${ }^{\dagger}$ Takuya Miyazaki, ${ }^{\dagger}$ Emi Aoki, ${ }^{\dagger}$ Hayato Sakai, ${ }^{\dagger}$ Taku Hasobe, ${ }^{\ddagger}$ Takahiko Kojima ${ }^{*,+}$ \\ +Department of Chemistry, Faculty of Pure and Applied Sciences, University of Tsukuba, 1-1-1 Tennoudai, Tsukuba, Ibaraki 305-8571, Japan \\ $\neq$ Department of Chemistry, Faculty of Science and Technology, Keio University, Yokohama, 223-8522, Japan \\ Supporting Information Placeholder
}

\begin{abstract}
Development of near-infrared (NIR) lightinduced hydrogen $\left(\mathrm{H}_{2}\right)$ evolution system is indispensable to construct a sustainable society to maximize the utilization of solar energy. Here, we report NIR light-driven $\mathrm{H}_{2}$ evolution catalyzed by a combination of a diprotonated saddle-distorted porphyrin as a photosensitizer and platinum nanoparticles as a $\mathrm{H}_{2}$-evolving catalyst. The quantum yield at $710 \mathrm{~nm}$ was determined to be $17 \%$, which is the highest value among photocatalytic $\mathrm{H}_{2}$-evolution systems ever reported.

KEY WORDS: near-infrared (NIR) light, diprotonated saddledistorted porphyrin, $\mathrm{H}_{2}$ evolution reactions (HERs), quantum yield, photoinduced electron transfer, photocatalysis
\end{abstract}

Hydrogen $\left(\mathrm{H}_{2}\right)$ is a promising and clean energy source for fuel cells to reduce the dependence on fossil fuels. ${ }^{1,2}$ Therefore, an efficient photocatalytic system capable of $\mathrm{H}_{2}$ evolution reactions (HERs) should be constructed on the basis of solar energy because $\mathrm{H}_{2}$ has been industrially manufactured by energy-consuming methods such as steam reforming of natural gas. ${ }^{2}$ To this end, extensive efforts have been devoted to developing photocatalytic HER composed of molecular photocatalysts and $\mathrm{H}_{2}$ evolution catalysts such as metal complexes or Pt nanoparticles (PtNPs). ${ }^{3-8}$ The archetypal photocatalysts ${ }^{9,10}$ mainly absorb visible lights to proceed photocatalytic HER efficiently, although the sun light contains not only UV-vis lights but also near-infrared (NIR) ones. Thus, the development of NIR light-responsible photocatalysts is indispensable to maximize the utilization of remaining solar energy for HER. However, there are a few limited examples to demonstrate NIR light-driven HER by heterogeneous semiconductors ${ }^{11,12}$ or metal complexes ${ }^{13-16}$ as photocatalysts, just affording low quantum yields (up to $4 \%$ ). Among organic photocatalysts, porphyrins are good candidates for NIR light-induced HER owing to their optical and redox properties based on the $18 \pi$ aromatic macrocyclic structure. ${ }^{17-19}$ So far, porphyrins have been employed as NIR light-responsible photosensitizers in photodynamic therapy

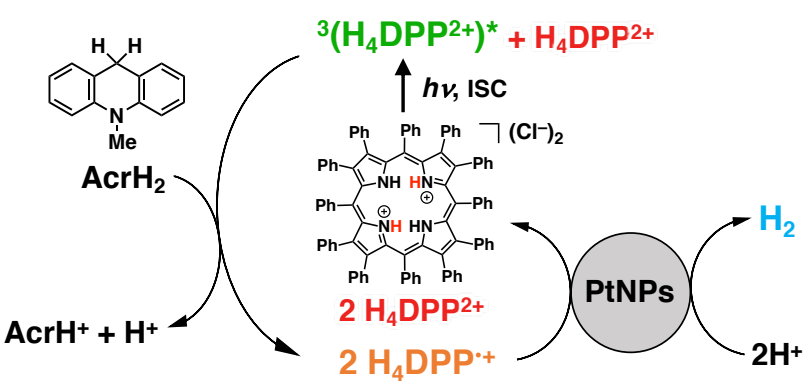

Scheme 1. Schematic Representation of the Approaches for Photocatalytic HER by $\mathrm{H}_{4} \mathrm{DPP}^{2+}\left(\mathrm{Cl}^{-}\right)_{2}$.

because light in the NIR range of $650-800 \mathrm{~nm}$ can only penetrate tissues effectively. ${ }^{20}$ In addition, the absorption bands of porphyrins could be extended $(\sim 750 \mathrm{~nm})$ by introducing distortion to the porphyrin core and the following diprotonation. ${ }^{11}$ Recently, a diprotonated saddle-distorted dodecaphenylporphyrin $\left(\mathrm{H}_{4} \mathrm{DPP}^{2+}\right)^{23}$ has been employed as a photoredox catalyst for photocatalytic oxidation of substrates $^{24}$ and oxygen reduction reaction ${ }^{25}$ based on the photodynamics and electron-transfer (ET) properties of $\mathrm{H}_{4} \mathrm{DPP}^{2+}{ }^{26-29}$ However, organic photocatalysts responsible to NIR lights have yet to be reported, which would open a development of NIR light-driven HER. We report herein a construction of an NIR light-driven $\mathrm{H}_{2}$ evolution system consisting of $\mathrm{H}_{4} \mathrm{DPP}^{2+}\left(\mathrm{Cl}^{-}\right)_{2}$ and PtNPs in the presence of an electron donor (Scheme 1). Evaluation of NIR light-driven HER was performed by a determination of initial rates of HER and quantum yields at the excitation wavelength, respectively.

Poly(vinylpyrrolidone)-protected PtNPs were synthesized according to the literature (see Experimental Section in the Supporting Information (SI)). ${ }^{30}$ The average size of PtNPs was determined to be $3.8 \pm 0.8 \mathrm{~nm}$ by transmission electron microscopy (TEM) measurements together with dynamic light scattering (DLS) measurements $(3.8 \pm 0.5 \mathrm{~nm})$ as shown in Figure S1. It should be noted that the best size of PtNPs for a HER catalyst has been reported to be around $4 \mathrm{~nm} .{ }^{31,32}$ Then, an elemental analysis of PtNPs afforded the weight ratio between PtNPs and poly(vinylpyrrolidone), resulting the determination of Pt contents $\left(0.16 \mathrm{mg} \mathrm{mL}^{-1}\right)$ in the stock solution of PtNPs (see Experimental Section in SI). 
We performed NIR light-driven HER under catalytic conditions by employing $\mathrm{H}_{4} \mathrm{DPP}^{2+}\left(\mathrm{Cl}^{-}\right)_{2}$ as a photocatalyst ${ }^{33}$ together with PtNPs as a $\mathrm{H}_{2}$ evolution catalyst and 10-methyl9,10-dihydroacridine $\left(\mathrm{AcrH}_{2}\right)$ as a two-electron donor in the presence of $p$-toluenesulfonic acid $(\mathrm{TsOH})$ as a proton source. Note that no interaction was detected between $\mathrm{H}_{4} \mathrm{DPP}^{2+}$ and PtNPs in the ground state, since no spectral change was observed in the UV-vis spectrum of $\mathrm{H}_{4} \mathrm{DPP}^{2+}$ upon addition of PtNPs (Figure S2). Photoirradiation $(\lambda=710 \mathrm{~nm})$ to a methanol $(\mathrm{MeOH})$ and acetonitrile $(\mathrm{MeCN})$ mixed solution $(1: 1 \mathrm{v} / \mathrm{v})$ containing $\mathrm{H}_{4} \mathrm{DPP}^{2+}$, PtNPs, $\mathrm{AcrH}_{2}$, and $\mathrm{TsOH}$ under Ar resulted in the efficient evolution of $\mathrm{H}_{2}$ detected by gas chromatography (GC). Several control experiments were performed in the absence of each component one by one to confirm the necessity (Figure S3), resulting all components are essential for promoting photocatalytic HER. In order to confirm the stoichiometry of HER, the amounts of products were quantified by UV-vis measurements during photocatalytic HER as shown in Figure 1a. An absorption band at $357 \mathrm{~nm}$ assigned to the oxidized product of $\mathrm{AcrH}_{2}$ $\left(\mathrm{AcrH}^{+}\right)$increased, although the absorption bands at $485 \mathrm{~nm}$ and $706 \mathrm{~nm}$ of $\mathrm{H}_{4} \mathrm{DPP}^{2+}$ were intact, indicating the robustness of $\mathrm{H}_{4} \mathrm{DPP}^{2+}$ under the catalytic conditions. The time profile of $\mathrm{H}_{2}$ evolution is almost consistent with that of $\mathrm{AcrH}^{+}$ formation (Figure $1 \mathrm{~b}$ ), which indicates that photocatalytic HER proceed almost stoichiometrically by consuming $\mathrm{AcrH}_{2}$ as a two-electron source (eq 1 ).

$$
\mathrm{AcrH}_{2}+\mathrm{H}^{+} \frac{h v, \mathrm{H}_{4} \mathrm{DPP}^{2+}, \mathrm{PtNPs}}{\mathrm{MeOH} / \mathrm{MeCN}=1: 1(\mathrm{v} / \mathrm{v})} \mathrm{AcrH}^{+}+\mathrm{H}_{2}
$$
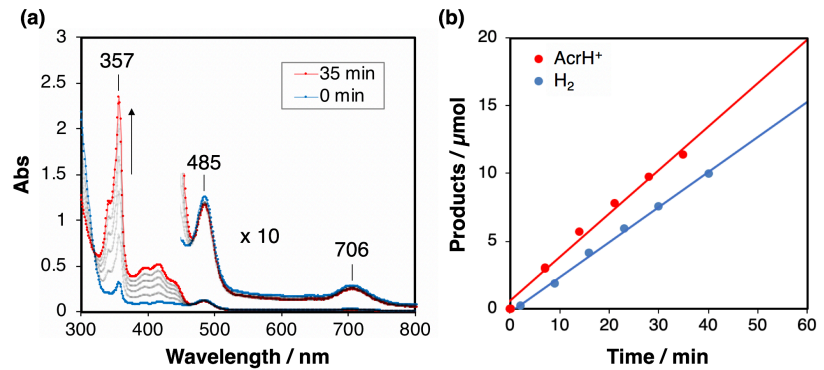

Figure 1. (a) UV-vis spectral changes in photocatalytic HER $(\lambda=710$ $\mathrm{nm}$ ) observed after a 20 -fold dilution. Conditions for HER: $\left[\mathrm{H}_{4} \mathrm{DPP}^{2+}\right]$ $=10 \mu \mathrm{M},[\mathrm{TsOH}]=30 \mathrm{mM},[\mathrm{PtNPs}]=0.15 \mathrm{mg} \mathrm{mL}^{-1},\left[\mathrm{AcrH}_{2}\right]=5 \mathrm{mM}$ in a $\mathrm{MeOH} / \mathrm{MeCN}$ mixed solution $(4 \mathrm{~mL}, 1: 1 \mathrm{v} / \mathrm{v})$ under $\mathrm{Ar}$ at $298 \mathrm{~K}$. (b) Time profiles of product amounts for $\mathrm{AcrH}^{+}$and $\mathrm{H}_{2}$.

Next, we investigated dependence of HER on the concentrations of PtNPs, $\mathrm{AcrH}_{2}$, acids, and $\mathrm{H}_{4} \mathrm{DPP}^{2+}$ to optimize the photocatalytic conditions. When the amount of evolved $\mathrm{H}_{2}$ was plotted against photoirradiation time, the initial rate of HER $\left(\nu_{\mathrm{H}}, \mu \mathrm{mol} \mathrm{min}{ }^{-1}\right)$ was determined on the basis of the initial slope of the plots (Figure S4). The dependence of $v_{\mathrm{H}}$ on the concentration of $\mathrm{AcrH}_{2}\left(\left[\mathrm{AcrH}_{2}\right]\right)$ showed saturation behavior (Figure 2a), suggesting that $\mathrm{AcrH}_{2}$ should be involved in a rate-determining step in
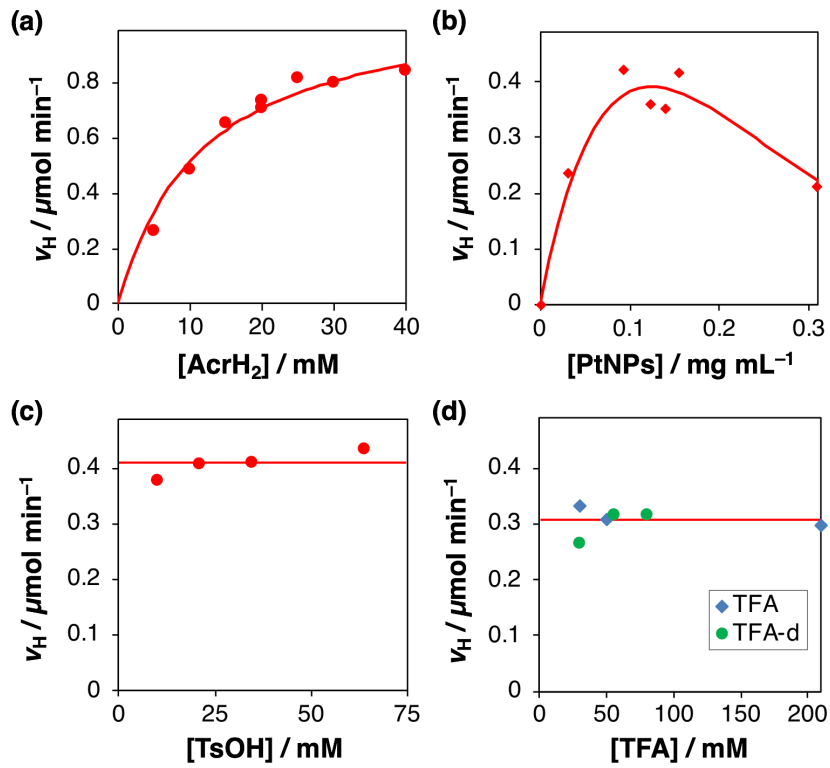

Figure 2. Plots of $v_{\mathrm{H}}$ vs (a) $\left[\mathrm{AcrH}_{2}\right]$ in the presence of $\mathrm{TsOH}(30 \mathrm{mM})$ and PtNPs $\left(0.15 \mathrm{mg} \mathrm{mL}^{-1}\right)$, (b) [PtNPs] in the presence of TsOH (30 $\mathrm{mM})$ and $\mathrm{AcrH}_{2}(10 \mathrm{mM}),(\mathrm{c})[\mathrm{TsOH}]$ and $(\mathrm{d})[\mathrm{TFA}]$ in the presence of PtNPs $\left(0.15 \mathrm{mg} \mathrm{mL}^{-1}\right)$ and $\mathrm{AcrH}_{2}(10 \mathrm{mM})$, under photocatalytic HER conditions $(\lambda=710 \mathrm{~nm})$ in a $\mathrm{MeOH} / \mathrm{MeCN}$ mixed solution (4 $\mathrm{mL}, 1: 1 \mathrm{v} / \mathrm{v})$ containing $\mathrm{H}_{4} \mathrm{DPP}^{2+}(10 \mu \mathrm{M})$ under Ar at $298 \mathrm{~K}$.

photocatalytic HER as discussed later. As for [PtNPs], a bellshaped dependence of $v_{\mathrm{H}}$ on [PtNPs] was observed within $0.30 \mathrm{mg} \mathrm{mL}^{-1}$, showing the highest performance in the range of 0.10-0.16 $\mathrm{mg} \mathrm{mL}^{-1}$, as shown in Figure 2b. In contrast, no dependence of $v_{\mathrm{H}}$ on $[\mathrm{TsOH}]$ was observed even in the case of a weaker acid such as trifluoroacetic acid (TFA) ${ }^{33}$ (Figure $2 c, d)$, indicating no correlation with the apparent proton concentration $\left(\left[\mathrm{H}^{+}\right]\right)$in the mixed solvent. Additionally, no kinetic isotope effect $\left(\mathrm{KIE}=v_{\mathrm{H}} / \mathrm{v}_{\mathrm{D}}=1\right)$ was observed, ${ }^{31}$ when deuterated TFA (TFA- $d$ ) was employed as depicted in Figure $2 \mathrm{~d}$. Judging from no dependence of $v_{\mathrm{H}}$ on acid concentrations and the lack of KIE, the formation of a putative Pt-H species between a Pt atom of reduced PtNP and a proton on the surface of PtNPs is not involved in the rate-determining step in contrast to the reported photocatalytic HER by using the same size of PtNPs. ${ }^{31}$ When we increased the concentration of $\mathrm{H}_{4} \mathrm{DPP}^{2+}$, the $v_{\mathrm{H}}$ value increased slightly with showing saturation behavior because the amount of absorbed photons at $710 \mathrm{~nm}$ increased with increasing $\left[\mathrm{H}_{4} \mathrm{DPP}^{2+}\right]$ owing to the elevated absorbance at $710 \mathrm{~nm}$ (Figure S5). In terms of quantum yields $(\Phi)$ based on the absorbed photons, no dependence of the $\Phi$ values on $\left[\mathrm{H}_{4} \mathrm{DPP}^{2+}\right]$ was observed, indicating $\mathrm{H}_{4} \mathrm{DPP}^{2+}$ acts as a photosensitizer rather than a $\mathrm{H}_{2}$ evolving catalyst.

Under the optimized photocatalytic HER conditions, a turnover number (TON) of NIR light-driven HER based on $\left[\mathrm{H}_{4} \mathrm{DPP}^{2+}\right]$ was reached 1500 at 3 hours with the $72 \%$ yield of $\mathrm{H}_{2}$ based on $\left[\mathrm{AcrH}_{2}\right]$ as shown in Figure 3. In order to interpret the saturation behavior of $v_{\mathrm{H}}$ vs photoirradiation time, repeated photocatalytic HER experiments were 


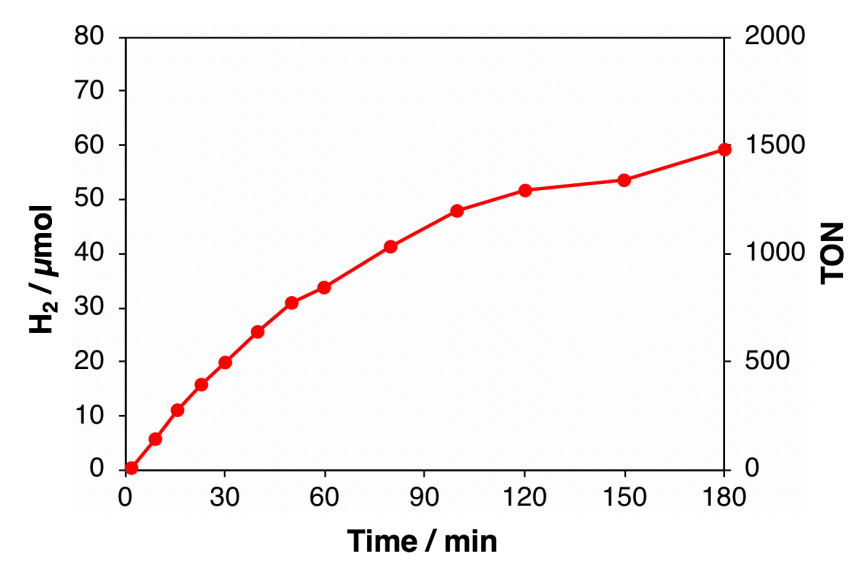

Figure 3. A time course of $\mathrm{H}_{2}$ evolution under photoirradiation $(\lambda=710$ $\mathrm{nm})$ in a $\mathrm{MeOH} / \mathrm{MeCN}$ mixed solution $(4 \mathrm{~mL}, 1: 1 \mathrm{v} / \mathrm{v})$ containing $\mathrm{H}_{4} \mathrm{DPP}^{2+}(10 \mu \mathrm{M}), \mathrm{AcrH}_{2}(20 \mathrm{mM}), \mathrm{TsOH}(30 \mathrm{mM})$, and PtNPs $(0.16$ $\left.\mathrm{mg} \mathrm{mL} \mathrm{m}^{-1}\right)$ under Ar at $298 \mathrm{~K}$.

performed by adding additional amount of $\mathrm{AcrH}_{2}$ and $\mathrm{TsOH}$ after $40 \mathrm{~min}$ photoirradiation. As a result, the same $v_{\mathrm{H}}$ values were obtained at least three times (Figure S6), ascertaining the robustness of this photocatalytic HER system. This result also suggests that the rate of photocatalytic HER depends on the concentration of $\mathrm{AcrH}_{2}$ without decomposition of $\mathrm{H}_{4} \mathrm{DPP}^{2+}$ and PtNPs. Surprisingly, the quantum yield $(\Phi)$ of photocatalytic HER was determined to be $17 \%$ at $710 \mathrm{~nm}$, $12 \%$ at $480 \mathrm{~nm}$, and $8 \%$ at $750 \mathrm{~nm}$ from the $v_{\mathrm{H}}$ values in Figure S7 by a photomultiplier and a comparative actinometer method (see Experimental Section). These $\Phi$ values at NIR regions are the highest ever reported in photocatalytic HER.

To gain a mechanistic insight into the photocatalytic HER, we performed nano-second laser flash photolysis (ns-LFP) in a mixed $\mathrm{MeOH} / \mathrm{MeCN}$ solution $(1: 1, \mathrm{v} / \mathrm{v})$. Upon photoexcitation at $532 \mathrm{~nm}$ to a deaerated $\mathrm{MeOH} / \mathrm{MeCN}$ solution of $\mathrm{H}_{4} \mathrm{DPP}^{2+}$ and $\mathrm{TsOH}$, transient absorption spectra of $\mathrm{H}_{4} \mathrm{DPP}^{2+}$ showed an absorption band at $560 \mathrm{~nm}$ at $0.8 \mu \mathrm{s}$ after laser excitation. This indicates the formation of the triplet excited state of $\mathrm{H}_{4} \mathrm{DPP}^{2+}\left({ }^{3}\left(\mathrm{H}_{4} \mathrm{DPP}^{2+}\right)^{*}\right)$ that showed a $\mu$ sorder lifetime ( $\tau=7.7 \mu \mathrm{s})$ via intersystem crossing (ISC) from the singlet excited state of $\mathrm{H}_{4} \mathrm{DPP}^{2+}\left({ }^{1}\left(\mathrm{H}_{4} \mathrm{DPP}^{2+}\right)^{*}\right)$ (Figure S8). ${ }^{26}$ Then, transient absorption spectra were measured in the presence of $\mathrm{AcrH}_{2}$ to investigate photoinduced electron transfer (ET) from $\mathrm{AcrH}_{2}$ to ${ }^{3}\left(\mathrm{H}_{4} \mathrm{DPP}^{2+}\right)^{*}$ (Figure 4a). The transient absorption spectrum changed to exhibit a new absorption band at $520 \mathrm{~nm}$, which was ascribable to the formation of the one-electron reduced $\mathrm{H}_{4} \mathrm{DPP}^{2+}$ $\left(\mathrm{H}_{4} \mathrm{DPP}^{++}\right){ }^{25,26}$ The decay time profile at $560 \mathrm{~nm}$ assigned to ${ }^{3}\left(\mathrm{H}_{4} \mathrm{DPP}^{2+}\right)^{*}$ coincided with the rise time profile at $520 \mathrm{~nm}$ due to $\mathrm{H}_{4} \mathrm{DPP}^{++}$as shown in Figure $4 \mathrm{~b}$. The second-order rate constant $\left(k_{\mathrm{et}}\right)$ of photoinduced ET from $\mathrm{AcrH}_{2}$ to ${ }^{3}\left(\mathrm{H}_{4} \mathrm{DPP}^{2+}\right)^{*}$ was determined to be $1.2 \times 10^{7} \mathrm{M}^{-1} \mathrm{~s}^{-1}$ by changing $\left[\mathrm{AcrH}_{2}\right]$ (Figure S9). Judging from the lifetime of ${ }^{3}\left(\mathrm{H}_{4} \mathrm{DPP}^{2+}\right)^{*}$ and the determined $k_{\mathrm{et}}$ value, the saturation behavior of $v_{\mathrm{H}}$ in Figure 2a was well explained by a competitive manner between ET from $\mathrm{AcrH}_{2}$ to ${ }^{3}\left(\mathrm{H}_{4} \mathrm{DPP}^{2+}\right)^{*}$ $\left(k_{\mathrm{et}}\left[\mathrm{AcrH}_{2}\right]\right)$ and the decay of ${ }^{3}\left(\mathrm{H}_{4} \mathrm{DPP}^{2+}\right)^{*}(1 / \tau)$ according to eq 2 . The fitting line based on eq 2 is completely consistent with the saturation behavior in Figure 2a, indicating the ratedetermining step in photocatalytic HER is the photoinduced ET from $\mathrm{AcrH}_{2}$ to ${ }^{3}\left(\mathrm{H}_{4} \mathrm{DPP}^{2+}\right)^{*}$.
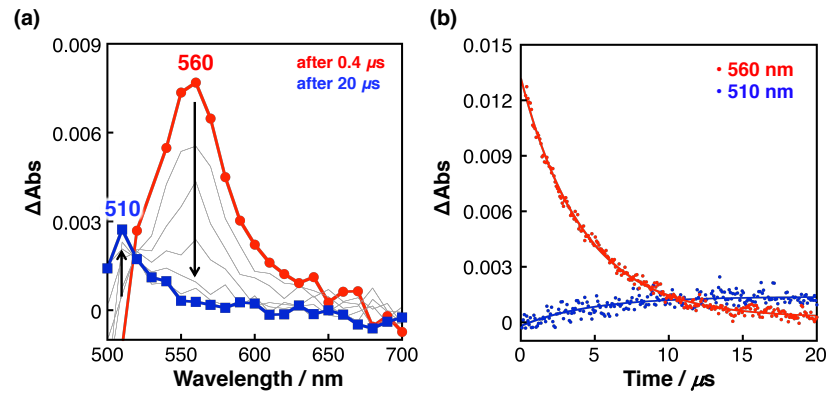

Figure 4. (a) Transient absorption spectra of $\mathrm{H}_{4} \mathrm{DPP}^{2+}(40 \mu \mathrm{M})$ in the presence of $\mathrm{AcrH}_{2}(12 \mathrm{mM})$ and $\mathrm{TsOH}(5 \mathrm{mM})$ in a deaerated $\mathrm{MeOH} / \mathrm{MeCN}$ mixed solution $(4 \mathrm{~mL}, 1: 1 \mathrm{v} / \mathrm{v}$ ) at $298 \mathrm{~K}$ taken at $0.4 \mu \mathrm{s}$ (red) and $20 \mu \mathrm{s}$ (blue) after nano-second laser excitation at $532 \mathrm{~nm}$. (b) The decay and rise time profiles at $510 \mathrm{~nm}$ (blue) and $560 \mathrm{~nm}$ (red) in photoinduced ET from $\mathrm{AcrH}_{2}$ to ${ }^{3}\left(\mathrm{H}_{4} \mathrm{DPP}^{2+}\right)^{*}$.

$$
v_{\mathrm{H}}=v_{\max } \frac{k_{\mathrm{et}}\left[\mathrm{AcrH}_{2}\right]}{k_{\mathrm{et}}\left[\mathrm{AcrH}_{2}\right]+1 / \tau}
$$

The proposed HER mechanism is described in Figure 5. Upon photoexcitation of $\mathrm{H}_{4} \mathrm{DPP}^{2+}$ in the presence of $\mathrm{AcrH}_{2}$, photoinduced ET from $\mathrm{AcrH}_{2}$ to ${ }^{3}\left(\mathrm{H}_{4} \mathrm{DPP}^{2+}\right)^{*}$ occurs to produce $\mathrm{H}_{4} \mathrm{DPP}^{\cdot+}$ as observed by ns-LFP. The fate of $\mathrm{AcrH}_{2}{ }^{\cdot+}$ was expected to form a radical species $\left(\mathrm{AcrH}^{*}\right)$ via the deprotonation and the resulting $\mathrm{AcrH}^{\cdot}$ species is capable of reducing another $\mathrm{H}_{4} \mathrm{DPP}^{2+}$. ${ }^{25,34}$ Subsequent electron injection directly from $\mathrm{H}_{4} \mathrm{DPP}^{++}$to PtNPs occurs to reduce a proton, affording a putative Pt-H species ${ }^{31,32}$ on the surface of PtNPs, to evolve $\mathrm{H}_{2}$ under catalytic conditions. Thus, we conclude that photoinduced ET from $\mathrm{AcrH}_{2}$ to $\mathrm{H}_{4} \mathrm{DPP}^{2+}$ and electron injection from $\mathrm{H}_{4} \mathrm{DPP}^{++}$to PtNPs allows us to construct the efficient photocatalytic HER system by NIR irradiation.

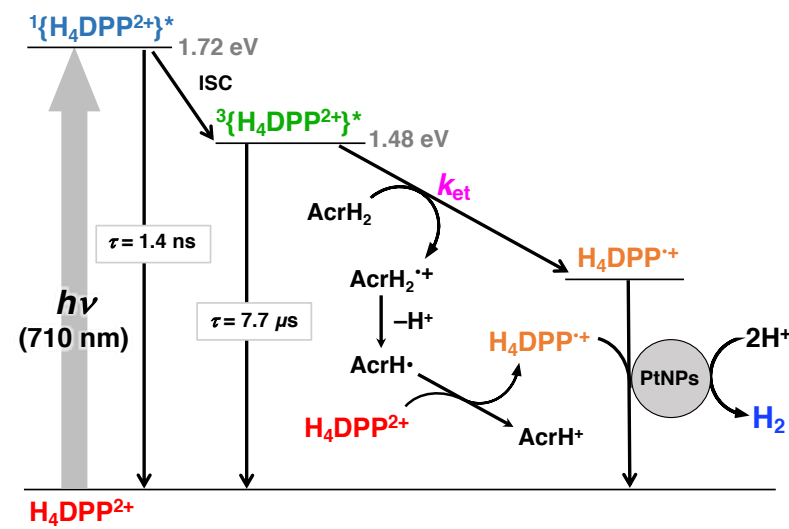

Figure 5. Proposed photocatalytic HER mechanism.

In conclusion, we have constructed NIR light-driven HER system composed of $\mathrm{H}_{4} \mathrm{DPP}^{2+}$ and $\mathrm{PtNPs}$ showing the highest 
quantum yield $\left(\Phi_{110}=17 \%\right)$ ever reported. The HER mechanism was clarified on the basis of nano-second laser flash photolysis and dependence of the HER rates on concentrations of PtNPs, $\mathrm{AcrH}_{2}$, and acids. The results presented herein are expected to contribute to the development of NIR light-driven HER by organic photocatalysts.

\section{ASSOCIATED CONTENT}

\section{Supporting Information}

Experimental details and kinetic data sets, including Figure S1-9.

\section{AUTHOR INFORMATION}

\section{Corresponding Author}

kojima@chem.tsukuba.ac.jp

\section{Notes}

The authors declare no competing financial interest.

\section{ACKNOWLEDGMENTS}

This work was supported by a Grant-in-Aid (17H03027) from the Japan Society of Promotion of Science (JSPS, MEXT) of Japan. Financial support through CREST (JST) is also appreciated (JPMJCR16P1).

\section{REFERENCES}

(1) Innovation, Markets and Sustainable Energy: The Challenge of Hydrogen and Fuel Cells; Pogutz, S., Russo, A., Migliavacca, P., Eds.; Edward Elgar: Cheltenham, UK; Northampton, MA, 2009.

(2) Armaroli, N.; Balzani, V. The Hydrogen Issue. ChemSusChem. 2011, 4, 21-36.

(3) Esswein, M. J.; Nocera, D. G. Hydrogen Production by Molecular Photocatalysis. Chem. Rev. 2007, 107, 4022-4047.

(4) Teets, T. S.; Nocera, D. G. Photocatalytic Hydrogen Production. Chem. Commun. 2011, 47, 9268-9274.

(5) Dempsey, J. L.; Brunschwig, B. S.; Winkler, J. R.; Gray, H. B. Hydrogen Evolution Catalyzed by Cobaloximes. Acc. Chem. Res. 2009, 42, 1995-2004.

(6) Han, Z.; Eisenberg, R. Fuel from Water: The Photochemical Generation of Hydrogen from Water. Acc. Chem. Res. 2014, 47, 2537-2544.

(7) Fukuzumi, S.; Lee, Y.-M.; Nam, W. Thermal and Photocatalytic Production of Hydrogen with Earth-Abundant Metal Complexes. Coord. Chem. Rev. 2018, 355, 54-73.

(8) Kaeffer, N.; Chavarot-Kerlidou, M.; Artero, V. Hydrogen Evolution Catalyzed by Cobalt Diimine-Dioxime Complexes. Acc. Chem. Res. 2015, 48, 1286-1295.

(9) Zhu, H.; Song, N.; Lv, H.; Hill, C. L.; Lian, T. Near Unity Quantum Yield of Light-Driven Redox Mediator Reduction and Efficient $\mathrm{H}_{2}$ Generation Using Colloidal Nanorod Heterostructures. J. Am. Chem. Soc. 2012, 134, 11701-11708.

(10) Li, X.-B.; Gao, Y.-J.; Wang, Y.; Zhan, F.; Zhang, X.-Y.; Kong, Q.Y.; Zhao, N.-J.; Guo, Q.; Wu, H.-L.; Li, Z.-J.; Tao, Y.; Zhang, J.P.; Chen, B.; Tung, C.-H.; Wu, L.-Z. Self-Assembled Framework Enhances Electronic Communication of Ultrasmall-Sized Nanoparticles for Exceptional Solar
Hydrogen Evolution. J. Am. Chem. Soc. 2017, 139, 47894796.

(11) Zhu, M.; Cai, X.; Fujitsuka, M.; Zhang, J.; Majima, T. $\mathrm{Au} / \mathrm{La}_{2} \mathrm{Ti}_{2} \mathrm{O}_{7}$ Nanostructures Sensitized with Black Phosphorus for Plasmon-Enhanced Photocatalytic Hydrogen Production in Visible and Near-Infrared Light. Angew. Chem. Int. Ed. 2017, 56, 2064-2068.

(12) Lian, Z.; Sakamoto, M.; Vequizo, J. J. M.; Ranasinghe, C. S. K.; Yamakata, A.; Nagai, T.; Kimoto, K.; Kobayashi, Y.; Tamai, N.; Teranishi, T. Plasmonic $\mathrm{p}-\mathrm{n}$ Junction for Infrared Light to Chemical Energy Conversion. J. Am. Chem. Soc. 2018, 141, 2446-2450.

(13) Rousset, E.; Chartrand, D.; Ciofini, I.; Marvaud, V.; Hanan, G. S. Red-Light-Driven Photocatalytic Hydrogen Evolution Using a Ruthenium Quaterpyridine Complex. Chem. Commun. 2015, 51, 9261-9264.

(14) Tsuji, Y.; Yamamoto, K.; Yamauchi, K.; Sakai, K. Near-Infrared Light-Driven Hydrogen Evolution from Water Using a Polypyridyl Triruthenium Photosensitizer. Angew. Chem. Int. Ed. 2017, 57, 208-212.

(15) Sayre, H. J.; Millet, A.; Dunbar, K. R.; Turro, C. Photocatalytic $\mathrm{H}_{2}$ production by Dirhodium(II,II) Photosensitizers with Red Light. Chem. Commun. 2018, 54, 8332-8334.

(16) Whittemore, T. J.; Xue, C.; Huang, J.; Gallucci, J. C.; Turro, C. Single-Chromophore Single-Molecule Photocatalyst for the Production of Dihydrogen Using Low-Energy Light. Nat. Chem. 2020, 12, 180-185.

(17) Dolphin, D. The Porphyrins V3 \& V5, Academic Press, New York, 1978.

(18) Ladomenou, K.; Natali, M.; Iengo, E.; Charalampidis, G.; Scandola, F.; Coutsolelos, A. G. Photochemical Hydrogen Generation with Porphyrin-Based Systems. Coord. Chem. Rev. 2015, 304-305, 38-54.

(19) Hasobe, T.; Sakai, H.; Mase, K.; Ohkubo, K.; Fukuzumi, S. Remarkable Enhancement of Photocatalytic Hydrogen Evolution Efficiency Utilizing an Internal Cavity of Supramolecular Porphyrin Hexagonal Nanocylinders Under Visible-Light Irradiation. J. Phys. Chem. C 2013, 117, 44414449.

(20) Sternberg, E. D.; Dolphin, D.; Brückner, C. Porphyrin-Based Photosensitizers for Use in Photodynamic Therapy. Tetrahedron 1998, 54, 4151-4202.

(21) Lash, T. D.; Chandrasekar, P. Synthesis of Tetraphenyltetraacenaphthoporphyrin: A New Highly Conjugated Porphyrin System with Remarkably Red-Shifted Electronic Absorption Spectra. J. Am. Chem. Soc. 1996, 118, 8767-8768.

(22) Röder, B.; Büchner, M.; Rückmann, I.; Senge, M. O. Correlation of Photophysical Parameters with Macrocycle Distortion in Porphyrins with Graded Degree of Saddle Distortion. Photochem. Photobiol. Sci. 2010, 9, 1152-1158.

(23) Medforth, C. J; Senge, M. O.; Smith, K. M.; Sparks, L. D.; Shelnutt, J. A. Nonplanar Distortion Modes for Highly Substituted Porphyrins. J. Am. Chem. Soc. 1992, 114, 98599869.

(24) Ishizuka, T.; Ohkawa, S.; Ochiai, H.; Hashimoto, M.; Ohkubo, K.; Kotani, H.; Sadakane, M.; Fukuzumi, S.; Kojima, T. A Supramolecular Photocatalyst Composed of a 
Polyoxometalate and a Photosensitizing Water-Soluble Porphyrin Diacid for the Oxidation of Organic Substrates in Water. Green Chem. 2018, 20, 1975-1980.

(25) Aoki, E.; Suzuki. W.; Kotani, H.; Ishizuka, T.; Sakai, H.; Hasobe, T.; Kojima, T. Efficient Photocatalytic ProtonCoupled Electron-Transfer Reduction of $\mathrm{O}_{2}$ by a SaddleDistorted Porphyrin as a Photocatalyst. Chem. Commun. 2019, 55, 4925-4928.

(26) Nakanishi, T.; Ohkubo, K.; Kojima, T.; Fukuzumi, S. Reorganization Energies of Diprotonated and SaddleDistorted Porphyrins in Photoinduced Electron-Transfer Reduction Controlled by Conformational Distortion. J. Am. Chem. Soc. 2009, 131, 577-584.

(27) Fukuzumi, S.; Honda, T.; Kojima, T. Structures and Photoinduced Electron Transfer of Protonated Complexes of Porphyrins and Metallophthalocyanines. Coord. Chem. Rev. 2012, 256, 2488-2502.

(28) Kielmann, M.; Senge, M. O. Molecular Engineering of FreeBase Porphyrins as Ligands-The N-H...X Binding Motif in Tetrapyrroles. Angew. Chem. Int. Ed. 2019, 58, 418-441.

(29) Suzuki, W.; Kotani, H.; Ishizuka, T.; Kojima, T. Dioxygen/Hydrogen Peroxide Interconversion Using Redox Couples of Saddle-Distorted Porphyrins and Isophlorins. J. Am. Chem. Soc. 2019, 141, 5987-5994.

(30) Wang, H.; Wang, Y.; Zhu, Z.; Sapi, A.; An, K.; Kennedy, G.; Michalak, W. D.; Somorjai, G. A. Influence of Size-Induced
Oxidation State of Platinum Nanoparticles on Selectivity and Activity in Catalytic Methanol Oxidation in the Gas Phase. Nano Lett. 2013, 13, 2976-2979.

(31) Kotani, H.; Hanazaki, R.; Ohkubo, K.; Yamada, Y.; Fukuzumi, S. Size- and Shape-Dependent Activity of Metal Nanoparticles as Hydrogen-Evolution Catalysts: Mechanistic Insights into Photocatalytic Hydrogen Evolution. Chem.-Eur. J. 2011, 17, 2777-2785.

(32) Zhou, M.; Bao, S.; Bard, A. J. Probing Size and Substrate Effects on the Hydrogen Evolution Reaction by Single Isolated Pt Atoms, Atomic Clusters, and Nanoparticles. J. Am. Chem. Soc. 2019, 141, 7327-7332.

(33) Under catalytic conditions employed in this study, $\mathrm{H}_{2} \mathrm{DPP}$ is completely diprotonated by acids used to be $\mathrm{H}_{4} \mathrm{DPP}^{2+}$. See: Suzuki, W.; Kotani, H.; Ishizuka, T.; Shiota, Y. Yoshizawa, K.; Kojima, T. Formation of Supramolecular Hetero-Triads by Controlling the Hydrogen Bonding of Conjugate Bases with a Diprotonated Porphyrin Based on Electrostatic Interaction. Chem. Commun. 2017, 53, 6359-6362.

(34) Fukuzumi, S.; Tokuda, Y.; Kitano, T.; Okamoto, T.; Otera, J. Electron-Transfer Oxidation of 9-Substituted 10-Methyl-9,10Dihydroacridines. Cleavage of the Carbon-Hydrogen vs. Carbon-Carbon Bond of the Radical Cations. J. Am. Chem. Soc. 1993, 115, 8960-8968. 
Insert Table of Contents artwork here

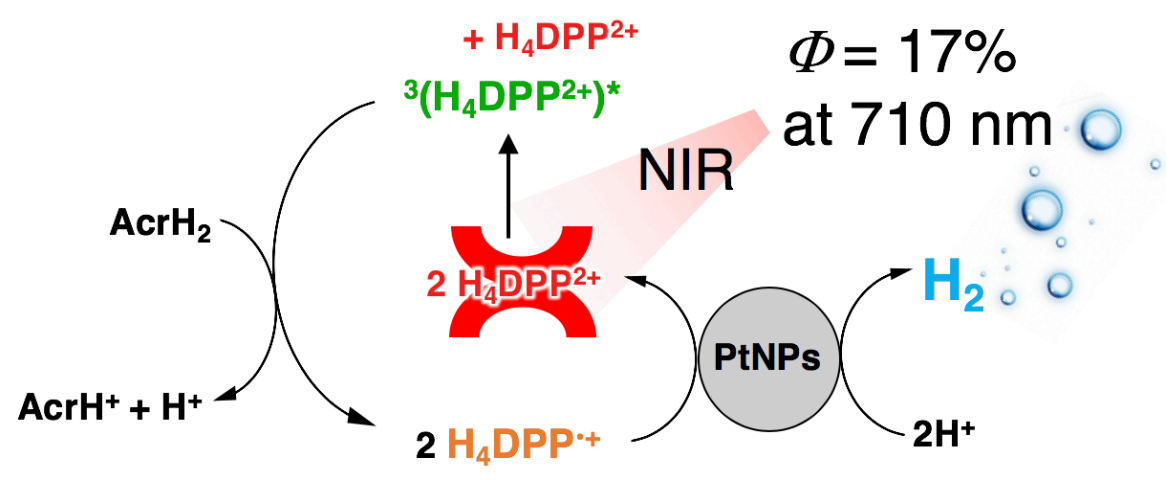

